\title{
Commentary: An aortic branch goes to the lung: So what?
}

\author{
Shawn P. Robinson, MD, and Ikenna C. Okereke, MD
}

\author{
From the Division of Cardiothoracic Surgery, University of Texas Medical Branch, Galveston, Tex. \\ Disclosures: Authors have nothing to disclose with regard to commercial support. \\ Received for publication April 1, 2019; accepted for publication April 2, 2019; available ahead of print May 15 , \\ 2019. \\ Address for reprints: Ikenna C. Okereke, MD, University of Texas Medical Branch, 301 University Blvd, Galves- \\ ton, TX 77555 (E-mail: ikokerek@utmb.edu). \\ J Thorac Cardiovasc Surg 2020;159:e17 \\ $0022-5223 / \$ 36.00$ \\ Copyright (c) 2019 by The American Association for Thoracic Surgery \\ https://doi.org/10.1016/j.jtcvs.2019.04.013
}

Fistulous connections between systemic arteries and the pulmonary vasculature and/or parenchyma are rare but have been increasingly described in the literature in recent times. ${ }^{1,2}$ Most of these reports have been individual cases, and the clinical status of the patients have ranged from no symptoms to significant bleeding. ${ }^{3,4}$ These fistulas can be congenital or acquired, and potential complications include hemoptysis, hemothorax, and pulmonary hypertension.

In their case presentation, Saito and Kawai describe an asymptomatic patient who was found to have a connection between a branch of the aorta and a small pulmonary artery within the lung parenchyma. ${ }^{5}$ The authors decided to operate because the diameter of the fistulous artery increased by more than 60 percent in 1 year. They performed a thoracoscopic ligation of the fistulous systemic artery and a wedge resection of the involved lung. Three important questions are raised from this case.

First, which patients with fistulous connections between a systemic artery and pulmonary artery require operation? Although fistulas between branches of the aorta and the pulmonary artery have been described as "rare," these fistulas are simply very enlarged bronchial arteries. As such, we should consider these connections on a spectrum and determine a size above which intervention is mandated. Because there is only sparse literature available concerning this topic, continued reports will have to be accumulated and analyzed to determine a high-risk diameter above which intervention is warranted. However, if a patient is asymptomatic and has a small fistulous artery seen on imaging, it is probably reasonable to observe that patient with surveillance imaging. Symptomatic patients should all undergo intervention.

Second, what is the optimal treatment? Saito and Kawai chose thoracoscopic ligation of the systemic vessel and a wedge resection of the involved lung because they observed dilated intraparenchymal arterial branches. But would percutaneous interruption of the systemic vessel have been enough, especially in an asymptomatic patient? It is quite possible that percutaneous embolization would have achieved the goal of preventing symptoms while avoiding thoracoscopy. If imaging shows that the fistulous vessel is

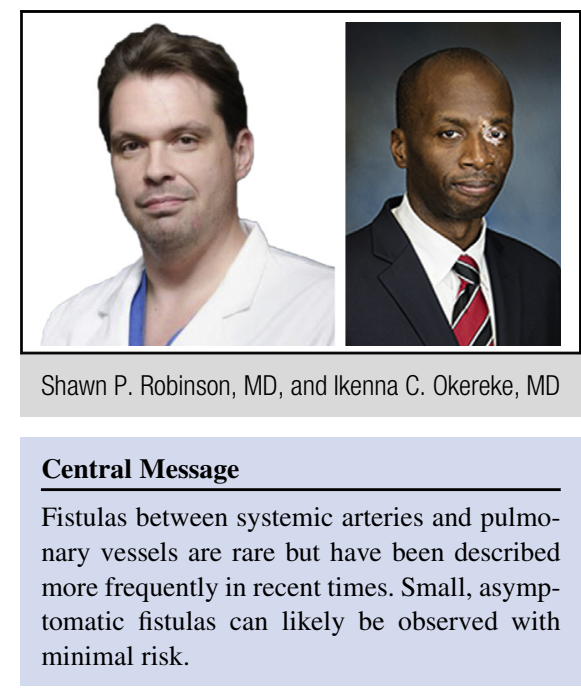

See Article page e13.

accessible, it is probably reasonable to attempt percutaneous intervention as the first line of treatment.

Third, is concomitant lung resection required? The authors saw several dilated, pulsating arterial branches on the lung surface and resected the lung to remove these abnormal vessels. If a clear structural abnormality is seen, lung resection should be performed. However, an anatomic resection should usually not be necessary, because these fistulas will usually connect with more peripheral aspects of the lung; when percutaneous intervention is chosen, surveillance imaging can be used to monitor the parenchyma for any concerning changes.

Fistulas between systemic arteries and the pulmonary vasculature will be reported more frequently with time. An algorithm on the basis of the diameter of the fistulous systemic artery, symptomatology, and parenchymal changes should be developed to care for patients without overtreating their condition.

\section{References}

1. Shi Y, Li Y, Lv X, Yang YH. Systemic-pulmonary arteriovenous fistulae with pulmonary hypertension: a case report. Medicine (Baltimore). 2018;97:e9959.

2. Li J, Zhai Z, Kuang T, Liu M, Ma ZH, Li YD, et al. A case of pulmonary hypertension due to fistulas between multiple systemic arteries and the right pulmonary artery in an adult discovered for occulted dyspnoea. Heart Lung Circ. 2017;26:e54-8.

3. Ansari-Gilani K, Gilkeson R, Hsiao E, Rajiah P. Unusual pulmonary arterial filling defect caused by systemic to pulmonary shunt in the setting of chronic lung disease demonstrated by dynamic 4D CTA. J Radiol Case Rep. 2015;9:17-23.

4. Vincze B, Lazar I, Mezei P, Almássy S, Tóth I. Spontaneous haemothoraxthoracic surgeon and intervention radiologist successful cooperation [in Hungarian]. Magy Seb. 2018;71:155-62.

5. Saito Y, Kawai H. Anomalous systemic arterial to right upper lobe pulmonary artery fistula: a case report. J Thorac Cardiothorac Surg. 2020;159:e13-5. 